\title{
FORMAÇÃO ON-LINE E PRATICANTES CULTURAIS: ELEMENTOS SÓCIO-HISTÓRICOS EM CONTEXTOS DE FORMAÇÃO NA CULTURA DIGITAL
}

\author{
Danilo Garcia da Silva ${ }^{1}$ \\ Katia Morosov Alonso ${ }^{2}$
}

\begin{abstract}
Resumo: Este texto resulta de uma pesquisa de maior amplitude em que se buscaram os entendimentos e percepções dos sujeitos da formação sobre os elementos sócio históricos da formação on-line (mediação, interação e interatividade) à luz dos processos formativos típicos da cultura digital. Trata-se de pesquisa com abordagem qualitativa e multirreferencial. Os sujeitos investigados foram os alunos, tutores e professores de cursos on-line no âmbito da Universidade Aberta do Brasil. Utilizou-se de análise documental, observação direta, questionários e entrevistas. Os achados da pesquisa apontam que os elementos sócio históricos são interdependentes e mantenedores das relações didático-pedagógicas promotoras de situações de aprendizagens. Evidencia também que, na cultura digital, a formação on-line decorre da mescla e de hibridizações de práticas que catalisam as ações que ocorrem em 'espaços' on-line e presencial.
\end{abstract}

Palavras-chave: Cultura digital; Elementos sócio históricos; Ambientes Virtuais de Aprendizagem.

\section{ONLINE FORMATION AND CULTURAL PRACTITIONERS: SOCIO- HISTORICAL ELEMENTS IN CONTEXTS OF FORMATION IN THE DIGITAL CULTURE}

\begin{abstract}
This text is the result of a broader research that sought the understandings and perceptions of the formation's individuals on the socio-historical elements of online formation (mediation, interaction and interactivity) in the light of the formative processes typical of digital culture. It is a qualitative and multi referential research. The subjects investigated were the students, tutors and teachers of the online courses of the "Open University of Brazil". Documentary analysis, direct observation, questionnaires and interviews were used. The results of the research indicate that the socio-historical elements are interdependent and maintain the didactic-pedagogical relations that promote learning situations. It also shows that, in digital culture, online formation is the result of a mixture and hybridization of practices that catalyze actions that take place in presential and on-line 'spaces'.
\end{abstract}

Keywords: Digital culture; Virtual Learning Environments; Socio-historical elements.

\footnotetext{
${ }^{1}$ Doutorado na área da Educação na linha de pesquisa Organização Escolar, Formação e Práticas Pedagógicas, pela Universidade Federal de Mato Grosso - UFMT. Vinculado ao grupo de pesquisa Laboratório de Estudos sobre Tecnologias da Informação e Comunicação - LêTece, do Instituto de Educação da UFMT. É professor no Departamento de Letras do Instituto de Linguagens da UFMT. É professor pesquisador no Programa de Pós-Graduação em Educação da UFMT (PPGE-IE/UFMT). Tem desenvolvido trabalhos com Ambientes Virtuais de Aprendizagem, Formação de Equipe TécnicoPedagógica em Ambientes Virtuais de Aprendizagem e no contexto de Tecnologias Digitais de Informação e Comunicação. Trabalha com Formação de Professores no contexto das TDIC na Educação, Tecnologias Educacionais e Educação a Distância/On-Line e Cultura Digital.

${ }^{2}$ Possui Graduação em Pedagogia pela Universidade Federal de Mato Grosso - UFMT, Mestrado em Educação pela Universidade Federal de Mato Grosso - UFMT e Doutorado em Educação pela Universidade Estadual de Campinas. É professora associada da Universidade Federal de Mato Grosso. Docente do Programa de Pós-Graduação em Educação - PPGE - do Instituto de Educação da UFMT. Líder do Grupo de Pesquisa Laboratório de Estudos Sobre Tecnologias da Informação e Comunicação na Educação - LêTece. Tem experiência na área de Educação, com ênfase em Educação a Distância, atuando principalmente nos seguintes temas: experiências em EaD/ tecnologias, uso das tecnologias da informação e comunicação -TIC na educação. Trabalha, atualmente, com pesquisa sobre as TDIC, com foco nos processos de interação e mediação.
} 


\section{INTRODUÇÃO}

A sociedade atual densamente imbricada por recursos e dispositivos tecnológicos retrata uma realidade de práticas e praticantes culturais que constituem aquilo que é a cultura digital. A cultura digital é uma cultura em constituição que denota um constante 'porvir', dadas as possibilidades de compartilhamento, remixagens, mesclas e hibridizações que refletem novas e outras maneiras de construção e socialização de conhecimento. A capilarização dos recursos e dispositivos das Tecnologias Digitais da Informação e Comunicação (TDIC) (KERCKHOVE, 2009) e consequente uso intensivo destes provocaram um atravessamento das relações humanas nos mais variados campos do conhecimento humano. Compartilhamento, remixagens, mesclas e hibridizações são elementos característicos da cultura digital, engendrados pelas alterações ocorridas no estabelecimento e manutenção das relações humanas. Naquilo em que nos interessam essas relações, detemo-nos àquelas instituídas nos espaços escolares pelas quais se constitui o pensar e o desenvolver de práticas formativas com o uso intensivo das tecnologias que, paulatinamente, complexificam os processos formativos, como se ensina e como se aprende.

Enquanto recursos das TDIC na educação, os Ambientes Virtuais de Aprendizagem (AVA) ganharam bastante projeção e, com isso, vêm denotando aquilo que temos de mais acabado e emblemático, pois por meio deles tem sido possível consubstanciar novas e diversificadas experiências formativas. Ampliaram e potencializaram-se as práticas educativas e as experiências de formação on-line em que as relações didático-pedagógicas tomaram traços progressivamente mais característicos da cultura digital.

Parte disso pode ser compreendido ao observarmos que, ao AVA, na sua grande maioria, se atribui uma base concebida na ideia do sociointeracionismo e, ainda, advogam a eles a possibilidade da mediação, interação e interatividade. Então, se eles sustentam tal compreensão, e se de fato eles vão subsidiar aquilo que são os processos de ensino-aprendizagem dos praticantes da cultura digital, essas constatações compõem dados em que precisamos investir desenvolvendo pesquisas para compreender como isso ocorre.

Com esta pesquisa, nosso foco se volta para os elementos sócio históricos da formação on-line: mediação, interação e interatividade em processos formativos típicos dos praticantes da cultura digital para compreendê-los em espaços de 
compartilhamento, remixagens, mesclas e hibridizações. Antes de avançarmos, importa salientar que este trabalho é um desdobramento de pesquisa anterior mais ampla realizada em nível de doutorado.

Ao focarmos a área da educação, a cultura digital imprime vários desafios, mas comporta um universo amplo de possibilidades formativas uma vez que permitem a convergência de dispositivos, recursos e mídias digitais plurais. Com isso, abre-se um amplo leque para a exploração de práticas e opções metodológicas. A formação on-line espelha a cultura digital, converte artefatos tecnológicos em recursos didáticopedagógicos que viabilizam o estabelecimento das relações e práticas sociais entre os professores, tutores e alunos. Esses artefatos, bases para a mediação, interação e interatividade permitem a disposição de relações em um continuum que transpõem e mantêm as relações didático-pedagógicas em prol da construção de conhecimento e desenvolvimento de aprendizagens.

A compreensão dos elementos sócio históricos tem em seu cerne a perspectiva sócio histórica (VYGOTSKY, 1996, 2000). Eles são, portanto, potencializadores de situações de aprendizagens e pilares das relações didático-pedagógicas nas trajetórias de formação on-line dos praticantes da cultura digital.

Inerentes à cultura digital, a ênfase é atribuída às práticas formativas e aos praticantes culturais que coexistem nas e pelas TDIC/AVA. Práticas formativas, praticantes culturais e recursos tecnológicos construindo e experienciando diferentes organizações do ensinar e aprender e diferentes estratégias e organizações pedagógicas que podem transitar de relações mais colaborativas e universalizadas às mais personalizadas e individualizadas. Isso porque as tecnologias convertem-se em artefatos culturais e, como tal, constituem-se em instrumentos simbólicos que se configuram nas relações entre os sujeitos e as práticas sociais e educacionais da cultura digital (VYGOTSKY, 1996; PRIMO, 2007; SILVA, 2001).

Para tratarmos do exposto acima, este artigo está organizado nas seguintes seções: nesta, fazemos a introdução da pesquisa, seguida dos aportes e referenciais teóricos. Posteriormente, temos uma seção em que fazemos a aproximação metodológica. E seguimos com os achados da pesquisa expondo o que foi evidenciado na investigação. Por fim, tratamos dos entrelaçamentos que compõem as considerações finais. 


\section{APORTES E REFERENCIAIS TEÓRICOS}

Para o que aqui denominamos de elementos sócio históricos da formação on-line (mediação, interação e interatividade), buscamos aporte nos trabalhos de Vygotsky (1996, 2000), Belloni (1999), Primo (2000; 2007), Silva (2001) e Valle e Bohadana (2012). São estes autores que subsidiaram nossas reflexões sobre a problemática posta em tela.

Em um apanhado de trabalhos levantados, os elementos sócio-históricos da formação on-line são tomados de maneira individualizada, isto é, não em conjunto. Identificamos que são variadas as temáticas e correspondem, em primeiro plano, à ampliação da mediação e à promoção da interação e interatividade dos processos educativos em AVA.

A aproximação com a perspectiva sócio-histórica (VYGOTSKY, 1996, 2000) nos dá condições para compreender que a mediação é a cultura que se torna parte da natureza humana em um processo histórico que molda o funcionamento psicológico do homem. Ela se configura como um processo e, como tal, caracteriza a relação do homem com o mundo e com outros homens, ocorrendo indiretamente. Pelo papel central no desenvolvimento humano, Vygotsky (1996) distingue dois tipos de elementos mediadores: os instrumentos e os signos. Os primeiros são aqueles que se interpõem entre o homem e o mundo/meio e que ampliam as possibilidades de transformação da natureza. E os últimos, aqueles que têm a linguagem como meio para estabelecer a comunicação. Então, é possível dizer que a capacidade de abstração ou representação mental, isto é, a capacidade de pensarmos em determinado objeto e de podermos imaginá-lo sem tê-lo opera como uma materialização deste objeto do mundo real. Este entendimento evidencia que a mediação oriunda de um sistema simbólico, a linguagem humana, atua entre o sujeito e o objeto de conhecimento. (VYGOTSKY, 1996).

Sobre a interação, neste caso, a interação humana, é possível considerá-la um modelo segundo o qual os interagentes realizam trocas, negociam e significam o ato comunicacional. Para Belloni (1999), a interação é tomada como ação entre os participantes de um encontro em que o foco dessa ação se direciona para a relação estabelecida entre os sujeitos interagentes, não havendo superioridade de um polo emissor, já que se busca valorizar a dinamicidade do processo, na qual todos os sujeitos interlocutores são atuantes na relação comunicacional. Na dimensão sociológica, a interação pode ser compreendida tanto como um processo de trocas estabelecidas entre 
dois ou mais indivíduos quanto como uma atividade social, o que vai caracterizar uma ação recíproca entre dois ou mais atores em que ocorre a intersubjetividade. (BELLONI, 1999). Então, com base na relação sujeitos-ambiente-sujeitos, - em que a relação dos praticantes da cultura digital visa ser plenamente interativa -, a interação é entendida no âmbito da relação interpessoal via recursos tecnológicos (PRIMO, 2000; 2007; BELLONI, 1999).

E, sobre a interatividade, constatamos que o termo tem sido empregado de maneira bastante elástica e difusa, sendo, portanto, recorrente nas pesquisas que investem nos desdobramentos da interação em ambientes virtuais ou, da interação com uso de recursos tecnológicos em que esteja implicado algum tipo de intervenção homem - máquina. Logo, a polivalência de emprego do termo interatividade vem adjetivar os recursos e dispositivos das TDIC (SILVA, 2001 e VALLE; BOHADANA, 2012) para atender uma exigência de operacionalidade imposta ao desempenho daqueles que, em algumas situações específicas, vislumbrou-se que os equipamentos pudessem vir a substituir, com vantagens de simplificação e rapidez, o contato humano direto. A interatividade traz em si a expectativa e a proposta de ideal de comunicação entre humanos, direta ou indiretamente mediada pelos recursos e dispositivos tecnológicos. Com relação a esse anseio, com as práticas e os praticantes da cultura digital face a um mundo progressivamente mais "automatizado e robotizado" (atendimentos eletrônicos, digitalizações, 'mundo digital'), preconiza-se a ruptura de modelos comunicacionais apregoando-se um modelo de comunicação que é ao mesmo tempo universalizado (massivo, para todos) e personalizado (interativo, pessoalidadeindividualidade) (LÉVY, 1994). Levando isso para a formação on-line de práticas e praticantes culturais de uso intensivo de tecnologias, daí a compreender que a interatividade evidencia formas outras de comunicação tanto entre os sujeitos da formação em si quanto com os recursos e dispositivos utilizados. Em meio a isso, são potencializadas a participação e intervenção que permitem a criação de espaços de atuação, contribuição e alternância de fluxos dos processos de desenvolvimento do curso mais diretos, imediatos e personalizados (FREITAS; DUTRA, 2009).

Diante disso, salientamos que dos trabalhos que se colocam à temática em tela, a presente pesquisa assenta-se na busca por preencher uma "lacuna" porque julgamos necessário contribuir no avanço de análises e reflexões que permitam melhor entender a relevância desses elementos nos cursos on-line à luz da cultura digital e de seus praticantes. Dito isso, passamos ao lócus e sujeitos da pesquisa. 


\section{APROXIMAÇÃO METODOLÓGICA}

A delimitação e característica do objeto em tela sinalizou um universo teórico metodológico de grande amplitude e rico para a apreensão dos fenômenos inerentes a ele. Assim, a pesquisa se sustentou na abordagem qualitativa e multirreferencial, de acordo com Denzin e Lincoln (2006) e Ardoino (1998). Enquanto instrumentos, lançamos mão da análise documental, observação direta, questionários e entrevistas.

No âmbito da cultura digital, optamos por trabalhar com cursos on-line, isto é, aqueles cursos realizados com o uso intensivo de recursos das TDIC/AVA e que, portanto, constitui o que se pode entender por formação on-line.

Aqui analisamos os achados da pesquisa que versam sobre uma dimensão dos praticantes culturais, a saber, alunos, tutores e professores. Os achados provêm do universo de 204 questionários e 39 entrevistas distribuídas entre os sujeitos citados. No caso da ocorrência de citações, adotamos a letra ' $S$ ' (para se referir a sujeito) seguida de um número que correspondeu à sequência da recolha (p. ex. sujeito 8 corresponde a S8).

Pela característica do objeto, o lócus de pesquisa foram cursos de formações online, isto porque esses cursos estavam propostos em práticas formativas de uso intensivo de recursos das TDIC, retratando, assim, fenômenos típicos da cultura digital. Portanto, optamos por trabalhar com os cursos que compunham o sistema da Universidade. Assim, selecionamos aqueles que atenderam ao critério estabelecido: possuir carga horária conclusa de $60 \%$ do período mínimo de integralização curricular. Quatro cursos contemplaram o respectivo critério. Já os sujeitos selecionados foram os participantes dos respectivos cursos que atenderam aos critérios: a) terem finalizado as atividades da última disciplina ofertada e encerrada; e b) tivessem maior e menor registros de participação no AVA do curso.

Com base nos critérios apresentados é que os achados da pesquisa foram recolhidos e organizados em núcleos de significação, como são explorados na continuidade do texto que segue. 


\section{ACHADOS DA PESQUISA: ELEMENTOS E PRATICANTES CULTURAIS E SEUS ENTRELAÇAMENTOS}

Daquilo que obtivemos como achados das pesquisas, observamos que há uma tessitura complexa das percepções e compreensões sobre os elementos sócio históricos da formação on-line em contextos da cultura digital. Igualmente, desvelou-se um entrelaçamento complexo e contínuo entre os respectivos elementos no decurso das trajetórias de formação dos praticantes culturais. Isso significa dizer que as trajetórias de formação na cultura digital são calcadas nos respectivos elementos que se entrelaçam nas/pelas práticas formativas que se mesclam e se hibridizam.

Em consonância com o viés metodológico em que se concebe um conjunto instrumental de recolha dos achados da pesquisa (projetos dos cursos, TDIC/AVA, questionários e entrevistas) é que se tornou possível organizar a pluralidade de olhares sobre o objeto investigado, bem como aprofundar demais questões que foram sendo levantadas durante a pesquisa. Disso, veio emergir um significativo escopo acerca dos entendimentos e percepções sobre os elementos sócio históricos da formação on-line no contexto da cultura digital.

Outro ponto é que a pluralidade referencial, bem como a riqueza dos olhares dos sujeitos vieram manifestar vários núcleos de significação. Porém, nosso foco nesta investigação dirige-se para os referidos elementos sócio históricos da formação on-line, considerando-os como processos formativos típicos dos praticantes da cultura digital para compreendê-los em espaços de compartilhamento, remixagens, mesclas e hibridizações.

$\mathrm{Na}$ cultura digital, atravessada por recursos e dispositivos tecnológicos nas diversas dimensões do conhecimento e do fazer humano, seus praticantes apresentam perfis bastante singulares. Já não está mais tão evidente, mesmo admitindo que exista uma diferença, se seriam homens ou mulheres que fazem mais uso dos recursos e dispositivos tecnológicos ou, ainda, aqueles de determinada faixa etária, mais ou menos jovens. É claro que com isso não queremos dizer que exista uma equidade, mas, restringimo-nos a pontuar que para estar e participar na cultura digital é preciso, antes de tudo, ter acesso tanto aos recursos e dispositivos quanto aos códigos e linguagens que são criados e disponibilizados pelos praticantes dessa cultura.

$\mathrm{Na}$ formação on-line não é diferente, dentre suas características, emerge que as práticas se sustentam em tecnologias (recursos, dispositivos e sujeitos em relação) pelos 
quais os praticantes constroem aprendizagens. Adentrando um pouco mais nesse ponto, os praticantes da cultura digital são aqueles que estudam, trabalham e interagem em redes e mídias sociais simultaneamente.

Isso anuncia que, pouco a pouco, não se tem uma medida perceptiva de divisão entre o tempo que se dedica às atividades distintas, como aos estudos e ao trabalho. Pela possibilidade de ação em dimensão e espaços-tempo "distintos", as práticas na cultura digital se mesclam e hibridizam sendo, portanto, orientadas por interesses que flutuam dos individuais e particulares para os sociais e coletivos e vice-versa. Parece-nos que, na formação on-line, cada vez mais os praticantes da cultura digital só reservam tempo para aquelas atividades formativas que exigem algum nível de formalização. Os próprios achados da pesquisa evidenciam que, na formação on-line, o aprender está em um não tempo, um não espaço, especialmente para aqueles que trabalham na mesma área da formação que estão cursando.

Mesmo considerando o movimento das práticas culturais alicerçadas e da formação on-line, os achados apontam que as práticas pedagógicas ainda carecem de ser ampliadas. Mesmo que na cultura digital ocorra o uso intensivo de tecnologias, os sujeitos não acumulam experiências educacionais significativas para a formação online. Eles são muito mais praticantes da cultura digital nas mais variadas situações do que, necessariamente, na educacional. Isso, inferimos que possa ser pelo fato de os sujeitos cursarem a primeira graduação on-line, isto é, a primeira formação característica da cultura digital com organização e sistematização didático-pedagógica específicas. Os sujeitos são muito mais afetos à conectividade e aos recursos e dispositivos em si. Com isso, ainda se encontram em descoberta das possibilidades da formação nômade pela qual o aprender é proveniente de redes de conexão que interligam pessoas independentemente de espaço físico definido para tal fim. O desafio parece ser despertar para as práticas culturais formativas que a ambiência de cultura digital abre.

Por outro lado, há aqueles praticantes culturais que, pelo desafio supramencionado, veem e usufruem de tudo aquilo que a cultura digital proporciona, porém como menos ênfase na educação. Mesmo assim, estes últimos sustentam o entendimento de que a formação on-line, nômade, exige conexões para a manutenção das relações com vista a aprendizagens. Isso significa dizer que para eles não há um espaço-tempo restrito para se aprender. Uma vez estabelecidas as relações pedagógicas, 
a qualquer lugar e a qualquer momento os elementos sócio históricos estão em ocorrência fomentando os processos de ensino-aprendizagem na formação on-line.

Os achados da pesquisa revelam que os recursos e dispositivos agregam potencial à formação na cultura digital por promover manutenção de nós que compõem uma cadeia de relações atravessada pelos elementos sócio-históricos.

Nesse oceano de possibilidades, o AVA é tomado como referência para os estudos sem, portanto, ser a única unidade catalisadora da formação. Mais adiante veremos que, mesmo tendo-o como referência, ocorre uma alternância e complementaridade de outros recursos e momentos de formação que não somente aqueles restritos ao AVA. Os achados indicam que a internet, apontada como o "nãolugar" preponderante para a formação, complementa os estudos e as trajetórias de formação além de ser referenciada como "facilitadora de busca livre de informações sobre o tema em estudo e discussão no AVA" e, também, pela "praticidade de realização de pesquisas direcionadas pelas referências bibliográficas indicadas nos materiais dos cursos".

De outro lado, os principais motivos arrolados para a utilização do AVA enquanto ambiente formal adotado pelos cursos é que, além de ele favorecer a realização das atividades do curso pela sua sistematização e organização didáticopedagógica, também é o elo das cadeias de interações que vão sendo construídas entre os sujeitos da formação.

O cenário que vai se configurando, vai se apresentando como típico da cultura digital. A transposição das ações e práticas formativas é resultado de um transbordamento dos percursos de estudos nos cursos. Tem-se, nos AVA, o gatilho deflagrador das trajetórias de formação que ecoa das interfaces e acompanhamento dos tutores, professores e colegas.

Em referência aos elementos sócio-históricos em questão nesta pesquisa, aos AVA se fazem alusões qualificativas de promotores desses elementos. Esses ambientes são, assim, "espaços" interativos, que agregam materiais concebidos em favor de promover o estabelecimento de relações com o 'outro', priorizando a dimensão social favorecida pelas condições técnicas dos processos que neles são instaurados e para além deles ressoam.

Então, os achados da pesquisa configuraram um cenário com espectro bastante amplo no que se refere às formas e "espaços" e à dedicação ao curso. 
Tanto que os sujeitos investigados, na condição de praticantes da formação online, desvelam que, para as trajetórias de formação, são dedicadas cerca de 3 a 10 horas semanais, distribuídas diariamente, específicas no AVA. Dentre esses sujeitos, surgiram aqueles que denotam certa dificuldade em dimensionar o tempo reservado aos estudos. Para esses, é evidente e necessário o desenvolvimento das atividades no AVA; entretanto, a formação on-line é uma dimensão do que fazem diariamente que, em essência, mescla todos os recursos e dispositivos de que dispõem, todas as informações relevantes que acessam e ou compartilham, todos os momentos e etapas do curso (encontros presenciais, interação com os colegas, orientações com os tutores e professores), todos os níveis e dimensões da participação no AVA e todo o tempo dedicado para qualquer atividade complementar, de interesse particular ou coletivo (busca de informação mais pontuais, encontro e interações com os colegas, professores e tutores) previstas ou não no curso. Logo, sendo estas as bases da formação, as práticas formativas não podem ser abarcadas por "espaços" únicos ou tempo e horários específicos. Então, a partir disso emergiu que a formação on-line é muito mais se se perceber como responsável imediato e assumir que o processo formativo exige rotina e dedicação como condição real para o êxito (PALLOFF; PRATT, 2004; 2002), porém ela não está restritamente atrelada ao AVA nem tampouco ao tempo depreendido para o cumprimento das atividades. Pelo contrário, é todo o tempo em que se está "conectado", todo "espaço" em que os praticantes se veem em relação com 'outros' e em todas as práticas culturais em que eles estejam despertos para algum aspecto ou dimensão da formação.

No sentido do que vimos expondo, outro ponto sobre o qual os achados nos facultam refletir é o de que os praticantes da formação on-line reconhecem os cursos on-line como dimensões das práticas culturais da cultura digital em que a educação está inserida. Isso importa porque esse tipo de formação veio em um movimento de compreensões de que ela seria uma maneira fácil de obter um diploma ou de opção única para aqueles com indisponibilidade de tempo e cuja flexibilidade de tempo e espaço era favorável e atrativa.

Pelo panorama que os achados vão revelando, o olhar sobre eles instituiu os núcleos de significação tratados na pesquisa. Neste ponto, convergiram os entendimentos e percepções dos praticantes da formação on-line sobre os elementos sócio históricos em tela, os quais sustentam os processos formativos típicos da cultura digital em espaços de compartilhamento, remixagens, mesclas e hibridizações. Para 
isso, o olhar para as trajetórias de formação e para todos os praticantes da formação: alunos, tutores e professores, foi fundamental para a compreensão da complexidade que aqueles processos envolvem.

Pelo já exposto, ao tomarmos como base a perspectiva sócio histórica, a mediação, a interação e a interatividade compõem o tripé basilar da formação on-line. Sobre elas, os achados da pesquisa evidenciaram uma estreita e coerente relação entre a mediação, a interação e a interatividade. Por conta disso, buscamos trabalhar esses elementos em suas particularidades mais individuais sem com isso "separá-los", mesmo porque as percepções e entendimentos dos sujeitos mostraram as relações e interdependências que os interligam e que permitiram ocorrer ao longo da formação. Como veremos, ainda que os elementos apresentem características que os permitam vincular a algum recurso ou dispositivo tecnológico, as 'operações' humanas é que se sobressaem e definem os contornos de sua ocorrência.

No tripé dos elementos em tela, duas grandes dimensões se sobressaíram para a mediação: uma mais vinculada à interação e, outra, ao papel dos tutores e professores. Para a primeira dimensão, a mediação é um elemento interdependente da interação, tendo nesta sua condicionante. Isso significa dizer que, para os sujeitos, em toda situação em que tiveram necessidade de mediação, ela ocorreu via interação. Assim, a mediação era um elemento requisitado para se suprir alguma carência ou dificuldade na apropriação dos conteúdos trabalhados no curso. Nas palavras dos sujeitos, "a mediação se dá através de interações com alunos, tutores e professores, a fim de alcançar o mesmo propósito de aprender, através de trocas de experiências. Não há mediação sem interação" (S49).

Para a segunda dimensão, a mediação é um elemento que está atrelado ao papel dos tutores e professores. Neste sentido, a mediação corresponde, em primeiro plano, às práticas realizadas pelos tutores e professores e, portanto, não existiria sem eles. Junto com os tutores e professores, os materiais dos cursos foram também apontados como elementos indicativos de mediação por subsidiarem as interlocuções dos tutores e professores com os alunos.

Nesse movimento, os elementos sócio históricos da formação on-line tomaram contornos mais evidentes de interação social sustentada pelas tecnologias, com o objetivo de manter os sujeitos da formação em relação com o 'outro'. É essa ideia que aparece com intensidade nos achados que tratam da interação. 
Em primeiro, a interação aparece como fomentadora de relações tanto pessoal quanto com o ambiente e materiais. $\mathrm{E}$, em segundo, como elemento vinculado às atividades do curso. E, por último, o ‘onde', o ‘como' e a 'frequência' das interações.

No âmbito da interação como fomentadora de relações, recebe destaque a formação on-line que poderia supor processos exclusivamente em rede, isto é, on-line. No entanto, o que se reitera é que ela subsidia o estabelecimento de relações que transbordam esse universo. A interação, tanto com os recursos e dispositivos tecnológicos quanto oriunda deles, promove e motiva encontros presenciais semanais ao invés de limitá-los.

Como vamos observando, os sujeitos não enxergaram as interações nos AVA como algo inerente a esse "espaço", nem tampouco aos processos formativos que fazem parte. $\mathrm{O}$ que se confirma é que a interação, tanto naquilo que seja on-line quanto pessoal e diretamente, é que faz com que a formação não seja algo distante e desprovido de sentido.

A interação, ao permitir a aproximação com o 'outro', dá credibilidade às relações didático-pedagógicas, estendem-nas e fortalecem as trajetórias de formação. Segundo os sujeitos, o contrário disso poderia exercer influência negativa e ruídos no processo de ensino e aprendizagem e acarretar em práticas formativas vazias. Importante analisar esse achado à luz da cultura digital que se vê atravessada pelas tecnologias em que as práticas culturais 'presenciais' ou 'virtuais' não são sobrepostas. Mas, pelo contrário, estão em patamares de complementaridade e convergência.

Isso corresponde a dizer que os cursos de formação on-line não descartam a importância de engajamento social no qual os sujeitos carecem de se inserir. Apenas, as relações são mediadas, em grande parte, pelas tecnologias. Aos praticantes da formação e, também, praticantes culturais, tutores e professores, compete justamente a responsabilidade em proporcionar a sociabilidade dos outros praticantes da formação, os alunos, colocando-os em relações mútuas tanto nos ambientes quanto pelos ambientes, mas não se restringindo a eles. Até porque, na ausência destas relações, emergem os prejuízos à interação social (VYGOTSKY, 1996, 2000) e, por consequência, à formação.

Quanto ao 'onde', ao 'como' e à 'frequência' da interação, pareceu haver um gatilho para sua deflagração durante a formação. Os achados indicaram que a interação surge motivada pelas atividades e sua frequência também se limita a elas. Portanto, há interação quando há atividades pedagógicas a serem realizadas no curso. De maneira 
semelhante ao que ocorre com a mediação, a interação também se atrela diretamente sendo, por sua vez, dependente daquela. Então, além das atividades, a dúvida sobre algum conteúdo ou atividade é outro elemento deflagrador da interação que, ao ser buscada, acarreta, por conseguinte a necessidade da mediação dos processos. Dito de outra maneira, atividades e dúvidas (tanto com os conteúdos quanto mais gerais) são estimuladores das interações e mediações com acentuada ênfase no fator social, momento em que os tutores se tornam os principais referentes do curso. Neste sentido, os encontros presenciais dos cursos relevam a importância dos tutores, como veremos mais à frente.

Conforme Palloff e Pratt (2002), o fator social prevalece, já que a relação que se estabelece nos cursos on-line possibilita manter os 'espaços' condizentes e favoráveis ao processo educativo. Isso não quer dizer que o 'conteúdo' da interação tenha valor estritamente significativo para quem estuda, mas pode ter agregado valores que mantenham o sentimento e o fortalecimento de uma comunidade de aprendizagem. Se não úteis diretamente ao conteúdo do curso, são úteis para a configuração de espaços de convivência vivos e dinâmicos uma vez que valorizam o acompanhamento das trajetórias formativas.

Para os sujeitos, a interação é um elemento muito importante no curso, seja ela pelos meios tecnológicos ou direta e presencialmente nos polos, desde que ocorra com os tutores. E, neste último caso, a relevância é sobre as interações nos encontros presenciais porque, segundo eles, quando houve boa interação presencial, as interações pelo AVA ficaram fortalecidas. E assim, para os sujeitos, os tutores são os legítimos professores do curso por serem os principais, quando não únicos, a estarem 'presentes', a acompanharem constantemente o curso e pela mediação que exerceram durante o processo formativo instaurado e, ainda, por intervirem junto aos professores face a alguma necessidade. Portanto, segundo os sujeitos, "a tutora (x) foi quem mais possibilitou [aprendizagens], pois ela dirimia todas as dúvidas, estava sempre bemdisposta para elucidar dúvidas" (S3).

E nesse universo, a mediação e a interação foram tomadas como complementares, imbricadas. Para os sujeitos, elas se sustentaram nas relações inauguradas nos encontros presenciais de início de curso e que, progressivamente, foram se estabilizando e se tornando mais fortes à medida que mais significado essas relações imprimiam nas práticas formativas. 
Uma questão importante a ser retomada é a alusão que os sujeitos fizeram sobre os encontros presenciais: os que inauguraram os cursos e os que ocorrem ao longo das disciplinas. Nesta pesquisa, um primeiro aspecto da formação on-line é ter sua proposta fundada em cursos on-line, concebidos para AVA e vislumbrando o uso intensivo de tecnologias, mas prevê também aqueles encontros presenciais supracitados. Entretanto, as dimensões da formação, aqui chamada presencial e on-line (no AVA), se fizeram por vias inversas. Ao não se restringir ao on-line, os alunos tinham a flexibilidade de dimensionar (via agendamento) os encontros presenciais no polo de atendimento e essa possibilidade de 'dosar' on-line e presencial imprimiu traços efetivos de presencialidade em algumas etapas do curso.

Todavia, mesmo nos momentos do trabalho presencial não se caracterizou uma formação dessa ordem. Porque o trabalho presencial no polo não era assistido senão pelo AVA do curso (o moodle). Ou seja, as práticas formativas reiteravam aquelas necessárias à formação de viés on-line, ainda que com o aditivo de tutoria presencial. E isso, a par e passo vai ratificando que as práticas formativas da cultura digital são atravessadas pelas tecnologias em que elas se constituem e resultam em mesclas e hibridizações.

Assim, os achados evidenciaram, em princípio, que a mediação e a interação se davam com os tutores. Mas, ao nos debruçarmos mais verticalmente sobre os achados da pesquisa, sobressaiu-se que os alunos se mantinham em constante e contínua relação e sem 'lugar' definido. Os alunos interagiam todas as vezes possíveis, independentemente da existência ou não de demandas do curso. Essas interações se davam em proporções complementares dos encontros presenciais e on-line, tanto pelo AVA como em outras redes e mídias sociais e face a face. Os sujeitos destacaram que essas interações eram muito favoráveis às necessidades particulares e de grupos para discussões diretas sobre os conteúdos ou atividades do curso ou, ainda, assuntos diversos relacionados ou não à formação.

Ao abordar o último pilar dos elementos sócio históricos, a interatividade, os entendimentos e percepções dos sujeitos seguiram vieses que se desenvolveram em gradações. Inicialmente, essas gradações partiram da indistinção entre interação e interatividade, passando pela característica inerente aos recursos e dispositivos tecnológicos, pelas próprias atividades do curso, e culminando na instantaneidade das relações entre os sujeitos. 
Dentre os termos tratados nesta pesquisa, a interatividade foi o mais complexo a ser trabalhado, tanto pela fluidez bem como pela elasticidade de uso da palavra. Diante disso, interação e interatividade seriam elementos indistintos e sinonímicos. Essa equivalência do termo veio expresso por: “[...] interatividade é o movimento de interação, então eu uso da tecnologia para fazer minha interação com o aluno ou tutor pelo ambiente virtual" (P8). Esse entendimento de interação mediada pelos recursos tecnológicos é tratado por Primo (2007) no âmbito da interação mediada por computador.

A inseparabilidade dos termos permitiu nuances em que, em dado momento, a interação correspondia às relações humanas 'diretas' (ou mediadas por TDIC) e, de outro, a interatividade correspondendo às relações homem-máquina. Portanto, a interatividade estaria, na disposição ou predisposição para mais interação (SILVA, 2001). Assim, é dada certa ênfase na dimensão humana quanto ao uso dos recursos tecnológicos no curso, atribuindo a eles um papel mediador nos processos que objetivaram pôr em relação os sujeitos. Vejamos o excerto que segue:

[...] a interatividade vem com a infotecnologia que causa mudanças de hábito no usuário-receptor, pois de passivo passa a operativo. Podemos simplificar a interatividade como um conhecimento sobre a mudança que opera no social. Essa interatividade ocorre porque uma de nossas ferramentas são meios tecnológicos, como a plataforma, os e-mails (S148).

Outro ponto surgiu quando a interatividade foi referenciada como atividades pedagógicas realizadas pelo grupo durante o curso. De acordo com essa perspectiva, o pressuposto interativo desloca-se do objeto (a atividade enquanto tarefa) para o sujeito. Não é somente o objeto, o material didático ou o artefato que adotam a característica de interativo, ou seja, não está na técnica. Mais do que isso, está no sujeito e naquilo que ele pode fazer no social com seus pares, no momento em que estabelecem relações em prol da resolução de determinado problema. Então, a compreensão que se estabelece é que a interatividade está no sujeito em interação. A atividade pedagógica aciona as relações interativas entre os sujeitos (os alunos) orientados pelos tutores e professores que, em processo interativo, almejam a conclusão de determinada atividade.

Por outro lado, a ênfase se desloca para o aspecto técnico da interatividade que a vinculou ao ambiente virtual utilizado no curso. Nesse sentido, os sujeitos advogam que “a interatividade esteve presente desde o início do curso. Por ser um curso [on-line] a 
distância, sem a interatividade não seria possível sua realização, uma vez que se refere ao ambiente virtual de aprendizagem" (S6).

Mesmo a associação da interatividade às tecnologias, em específico ao AVA do curso, não a restringe nem a isola em si mesma, porque é considerada na potencialização de processos interativos entre os sujeitos, otimizando a interação e a comunicação entre eles. Tal associação faz referência à interação homem-máquina, sendo que aqui os sujeitos da pesquisa demonstram compreender que

[...] a tecnologia disponível hoje permite a implementação de ambientes de intensa interação, longe da pré-determinação estrita, onde os interagentes podem agir criativamente entre eles. Onde a comunicação possa ter lugar, sem que cada agente fique preso à relação ação-reação ou adequar-se a inputs determinados que geram sempre e necessariamente os mesmos outputs (PRIMO; CASSOL, 1999, p. 66).

A alusão direta da interatividade como o ambiente dos cursos se reiterara de forma bastante gradativa: “[...] a interatividade é tudo o que o ambiente virtual representa, onde há possibilidade de novas aprendizagens" (S141); “[...] a interatividade tem relação com a tecnologia, que viabiliza a interação entre duas ou mais pessoas. Entendo que essa interatividade ocorreu no curso por meio da plataforma de ensino, que possibilitou a interação dos alunos [...] importantes para o aprendizado" (S175).

Nesta dinâmica, qualquer variabilidade de discurso convergia em vincular a interatividade à simultaneidade, com foco no feedback dos tutores e professores. Nestes casos, a interatividade foi referenciada como o tempo-espaço da interlocução, expresso como a resposta ou o retorno às atividades, ou aos questionamentos dos alunos durante o curso. Assim, palavras como simultâneo, instantâneo e breve foram invocadas recorrentemente para ilustrar o processo dialógico esperado na formação on-line em ‘tempo e espaço' que atendesse às necessidades dos interlocutores. É fato que as respostas ou o feedback devem ocorrer em tempo hábil para a construção ou elaboração de conhecimento de quem é portador da dúvida. Isso provoca um retorno de informação e a negociação de sentido para que o sujeito possa construir e/ou apropriar-se do conhecimento. Se pensarmos unicamente no tempo de retorno, aquilo que se compreende por acompanhamento de processo formativo tende a se reduzir a fornecimento de feedbacks ou respostas, e isso os sistemas informáticos o fazem muito bem. Apesar de a interatividade trazer uma configuração nova à formação on-line, esta 
não se pode resumir a fornecer meras respostas pontuais e estanques senão para subsidiar reflexões e orientar as trajetórias de formação.

A simultaneidade, instantaneidade e brevidade talvez estejam mais vinculadas à possibilidade de realizar, sim, um processo "junto on-line", sem deixar que a inerente distância provoque uma quebra na relação entre os sujeitos envolvidos em um processo contínuo, organizado, sistematizado, acompanhado e avaliado, que se desenvolve em movimento e pela relação, sem interromper o fluxo intercomunicativo que os cursos nestes formatos exponencialmente exigem. E, ao retomarmos a linguagem enquanto elemento de mediação simbólica (feita pelos signos), as interlocuções constituem-se de processos ampliados de mediação pelas relações estabelecidas.

Portanto, a nosso ver, o que se vislumbrou não foi a dicotomização: de um lado as tecnologias e de outro, os sujeitos, mas um processo que dê retorno rápido ao aluno como mais importante do que entender as circunstâncias em que se realizam tal ou tais indagações. Em outras palavras, tendo a interatividade uma aproximação e relação estreitas com e pelas tecnologias, o consequente apressamento que as exigências contemporâneas (e as formações) possam suscitar não faz com que a lógica dessas tecnologias atropele o tempo que a aprendizagem exige, e substitua o processo de aprendizagem pelo mero fornecimento de feedback ou respostas, afastando a possibilidade que é a de "estar e ir junto on-line" com os sujeitos em formação.

Dados os achados que vimos apresentando sobre os elementos sócio históricos da formação on-line, veio sendo evidenciada a insociabilidade deles sob pena de redução e simplificação dos processos que foram instaurados. A mediação, interação e interatividade formulam um conjunto de condições promotores de situações de aprendizagens nos contextos investigados.

Pela significância dos elementos antes mencionados, os achados nos incitaram a refletir sobre as práticas formativas típicas da formação on-line, isto é, se aquelas restritas aos 'espaços' e relações on-line eram suficientes para os processos formativos ou, no limite, para a produção e apropriação de conhecimento e, especialmente, para as aprendizagens nos cursos.

Diante disso, os achados apontaram que, associados ao 'gosto por estudar e aprender', os elementos motivam a permanecer no curso pelas possibilidades de aprendizagens que se abriram. As práticas que ocorreram na formação fortaleceram seu caráter relacional e interativo. 
Observada a importância dos elementos sócio históricos da formação on-line, quando minimizados ou ausentes, eram buscadas estratégias para fomentá-los. Quando eram intensos, ocorria o transbordamento daquilo que acontecia na dimensão on-line que convergia nas relações presenciais. Sem dar ênfase a um ou outro elemento sócio histórico e reconhecendo o potencial de todos, os achados permitem ponderar que a interação foi a base que deu condições não só para a mediação como também para a interatividade.

No conjunto do curso, materiais, ambiente e sujeitos, os achados advogaram em favor das práticas educativas e trajetórias de formação instauradas. Sobre o ambiente moodle e os materiais do curso revelou-se que eles estiveram organizados e com atividades bastante interativas.

Dito isso, finalizamos as principais evidenciações que a pesquisa nos permitiu e que o espaço deste texto nos possibilitou discutir, passando na sequência às considerações finais.

\section{DOS ELEMENTOS QUE SE ENTRELAÇAM AO LONGO DAS TRAJETÓRIAS FORMATIVAS: CONSIDERAÇÕES FINAIS}

Importa salientar que o trabalho aqui lançado se direcionou a compreender os elementos sócio históricos da formação on-line, entendendo esta como proposta formativa com uso intensivo de recursos e dispositivos tecnológicos, ênfase nos AVA. E, também, como formação inerente à cultura digital em que as práticas e os praticantes da formação (alunos, tutores e professores) são os mesmos, isto é, praticantes dessa cultura.

Para olharmos para a formação on-line em meio à cultura digital, assentamo-nos na perspectiva sócio histórica, tendo em Vygotsky $(1996,2000)$ nossa principal âncora. Tendo por foco os elementos sócio históricos da formação on-line em processos formativos típicos da cultura digital, vislumbramos a multirreferencialidade como possibilidade de apreensão de níveis mais complexos sobre os entendimentos e percepções dos sujeitos sobre o objeto em investigação. Com isso, os achados desnudam multirreferências e olhares plurais sobre os fenômenos formativos on-line em que os sujeitos da formação, praticantes culturais, lançaram sobre os elementos sócio históricos. Da complexidade que os fenômenos formativos têm, os achados revelam características importantes do processo em que a mediação, interação e interatividade não ocorrem de maneira independente e individualizada. Pelo contrário, elas se fazem 
em tríade e, ao vincular as relações dos sujeitos-ambientes-sujeitos com os quais esses mesmos sujeitos vão construindo suas trajetórias de formação, a ocorrência de uma não encerra a outra. Mediação, interação e interatividade firmam e sustentam as relações didático-pedagógicas promotoras de práticas, ações e situações de aprendizagens.

Avesso ao que se poderia imaginar, à priori, a formação on-line de uso intensivo de tecnologias não se compreende somente por aquilo que seja o on-line, em específico o AVA. A complexidade que envolve esses processos formativos demonstrou que as práticas se fizeram ancoradas em relações tanto on-line quanto presenciais. Assim, a formação se deu em meio a transbordamentos das práticas formativas em função da promoção dos elementos sócio históricos independentes dos 'espaços'. Portanto, a formação on-line caracterizou-se por mesclas e hibidrizações das relações didáticopedagógicas. Corresponde dizer que nem o AVA, nem os encontros presenciais com tutores, professores e alunos encerravam formativas suficientes. Quando os elementos sócio históricos estavam ausentes das práticas formativas no AVA, os sujeitos buscavam estratégias para promovê-los tanto na dimensão on-line quanto presencial. Do mesmo modo, o inverso também ocorreu, o transbordamento dos respectivos elementos e das respectivas práticas no AVA mobilizavam os sujeitos à manutenção das relações a eles favoráveis.

Por fim, a formação on-line se caracterizou pela mescla e hibridização dos elementos sócio históricos em fluxo contínuo e interdependente que permearam as trajetórias formativas no âmbito da cultura digital. Logo, mediação, interação e interatividade cumprem função essencial ao processo de ensino e aprendizagem e estabilizam as relações entre os sujeitos-ambiente-sujeitos, praticantes formativos e culturais.

\section{REFERÊNCIAS}

ARDOINO, Jacques. Abordagem multirreferencial (plural) das situações educativas e formativas. In: BARBOSA, Joaquim Gonçalvez (coord.). Multirreferencialidade nas ciências e na educação. São Carlos: EdUFSCar, 1998.

BELLONI, Maria Luiza. Educação a distância. 3. ed. Campinas: Autores Associados, 1999.

BELLONI, Maria Luiza. Ensaio sobre a educação a distância no Brasil. Educação \& Sociedade, ano XXIII, n. ${ }^{\circ}$ 78, abr. 2002. 
DENZIN, Norman K.; LINCOLN, Yvonna S. O planejamento da pesquisa qualitativa: teorias e abordagens. Tradução Sandra Regina Netz, 2. ed. Porto Alegre: Artmed, 2006.

FREITAS, Rejane Cunha; DUTRA, Marlene de Alencar. Usabilidade e Interatividade em Sistemas Web para Cursos Online. Revista Brasileira de Informática na Educação. v. 17, n. 2, p. 48-58, mai./ago. 2009. Disponível em: < http://www.brie.org/pub/index.php/rbie/article/view/98 > . Acesso em: 15 jan. 2018

KERCKHOVE, Derrick de. A pele da cultura: investigando a nova realidade eletrônica. 1ed. São Paulo: Annablume, 2009.

LÉVY, Pierre. A emergência do cyberspace e as mutações culturais. Porto Alegre, out. 1994. Palestra realizada no Festival Usina de Arte e Cultura, promovido pela Prefeitura Municipal de Porto Alegre. Disponível em: < http://www.caosmose.net/pierrelevy/aemergen.html >. Acesso em: 28 jan. 2018.

PALLOFF, Rena M.; PRATT, Keith. O aluno virtual: um guia para trabalhar com estudantes on-line. Porto Alegre: Artmed, 2004.

PALLOFF, Rena M.; PRATT, Keith. Construindo comunidades de aprendizagem no ciberespaço. Porto Alegre: Artmed, 2002.

PRIMO, Alex; CASSOL, Marcio Borges Fortes. Explorando o conceito de Interatividade: definições e taxonomias. Informática na Educação: teoria \& prática. Porto Alegre, v. 2, n. 2, p. 65-80, 1999.

PRIMO, Alex. Interação mútua e reativa: uma proposta de estudo. Revista da Famecos. n. 12, p. 81-92, jun. 2000.

PRIMO, Alex. Interação mediada por computador: comunicação, cibercultura, cognição. Porto Alegre: Sulina, 2007.

SILVA, Marco. Sala de Aula Interativa. Rio de Janeiro: Quartet, 2001.

VALLE, Lílian do; BOHADANA, Estrella D'alva Benayon. Interação e interatividade: por uma reantropolização da EaD online. Educ. Soc. [online]. 2012a, v.33, n.121, pp. 973-984. ISSN 0101-7330.

VYGOTSKY, Lev Semionovitch. A Formação Social da Mente. 5. ed. Trad. José Cipolla Neto, Luis S. M. Barreto e Solange C. Afeche. São Paulo: Martins Fontes, 1996.

A construção do pensamento e da linguagem. Trad. Paulo Bezerra. São Paulo: Martins Fontes, 2000. 